\title{
MANAGING CONTRACTS IN VIRTUAL PROJECT SUPPLY CHAINS
}

\author{
Heli Laurikkala and Kari Tanskanen \\ Tampere University of Technology, Machine Design, P.O. Box 589, 33101 Tampere, \\ FINLAND \\ tel.+35833653665, fax.+35833652307, heli.laurikkala@tut.fi, kari.tanskanen@tut.fi
}

\begin{abstract}
The paper studies the management of contracts in virtual project supply chains. The problems and challenges occurring as well as the business practices and typical project structures in a networked environment are discussed. The concentration is on large, complex, one-of-a-kind projects and the case companies are from the field of power plants. The paper also introduces means to support the contract management of virtual project organizations by using the strategic information system called Simo-3.
\end{abstract}

\section{INTRODUCTION}

In a large, complex project, the amount of contracts written is numerous. The contracts are large as well, containing detailed information in tens of pages. Still, different terms and standards cause misunderstandings and delays in project schedule, making risk management difficult. There is a need for a common, simpler format for a contract.

In a networked environment, the complexity still increases. It brings new difficulties for virtual supply chains the most important of which is the insufficient information flow between the networked participants. They lack proper information systems to support their co-operation and to increase their competitiveness.

The aim of the paper is to study the management of contracts in virtual project organizations: the problems and challenges the companies have to face when working in a networked environment. It concentrates on large, project-oriented companies. The case companies are from the field of power plants. The paper also introduces means to support the contract management of virtual project supply chains with the help of the strategic information system called Simo-3.

Virtual organizations are widely studied in the current literature. Chandrashekar and Schary (1999) study virtual supply chains and the convergence of information technology and organization. Evaristo and Fenema (1999) concentrate on virtual projects and the evolution of new forms of project management.

Management of contracts is getting more and more important for researchers and practitioners in the field of project management. Gaythorpe (1999) describes his experiences on many UK and international projects, attempting to identify the

The original version of this chapter was revised: The copyright line was incorrect. This has been corrected. The Erratum to this chapter is available at DOI: 10.1007/978-0-387-35585-6_68 
problems occurring in contract management and completion. Cullen (2000) concentrates on legal issues of contracting and extended enterprises.

Contract management is often closely linked to risk management, which is also one of the main topics of interest for researchers. Raz and Michael (2001) discuss the use and benefits of tools for project risk management. They also study different variations of project risk management process (PRM). Pender (2001) asks why risk management is not sufficient and studies the management of incomplete knowledge. Baccarani and Archer (2000) study the risk ranking of projects, also from the contract management point of view. Martin (2000) has developed a simulation engine for custom project management education which models a contract management approach in large construction project. Tan and Thoen (2000) present a legal expert system for trade contracts. Still, there are only a few studies about contract management in virtual project organizations and supply chain.

The project was started with a study about future networking strategies of four case companies. The lawyers of the companies were interviewed for creating a contract format for common use. State-of -the-art study about related modelling methods, existing tools and practices followed. The case study approach was used when creating and testing a new tool for multi-project management of networked project-oriented companies.

\section{BUSINESS PRACTICES OF PROJECT-ORIENTED COMPANIES}

\subsection{Business Environment}

Business environment of networked multi-project oriented companies is a complex one (Figure 1). There are many problematic situations related to e.g. preliminary planning, contracting, scheduling and logistics, which cannot properly be solved without an efficient information system.

A turnkey project (Figure 2) is the most typical project structure in the field of large, one-of-a -kind projects. The main contractor is responsible for planning and construction as well as for the procurement of machinery, equipment and materials and, after completion of the project, delivers the ready-to-use entity to the customer. A turnkey delivery is possible in all the size variations (small-medium-large). The contractor may though try to transfer part of its contractual liability to its subcontractors or have stricter terms with them.

A project may also be subdivided into smaller entities. This is typical for small plants. The customer signs separate contracts for boiler, piping, automation, building, steel works etc. with suppliers who in turn make their own subcontracts. Responsibility lies with the highest level. For more information about project structures, see (Laurikkala et al, 1999). 


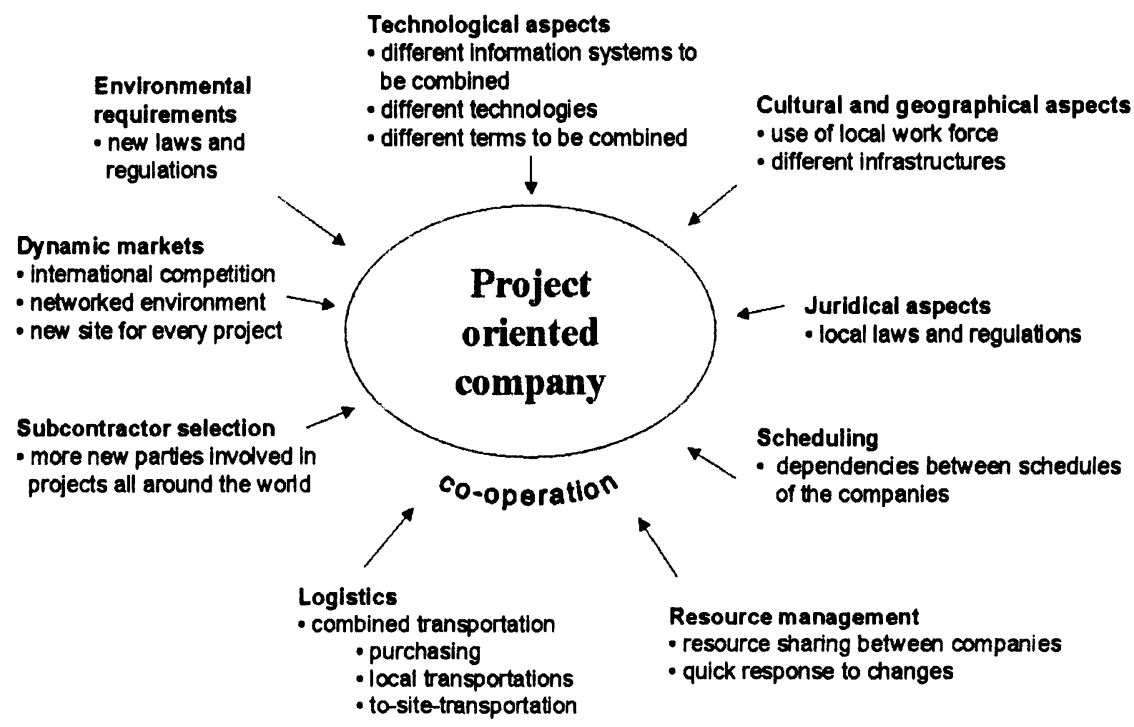

Figure 1 - Business environment of a networked, multi-project oriented company

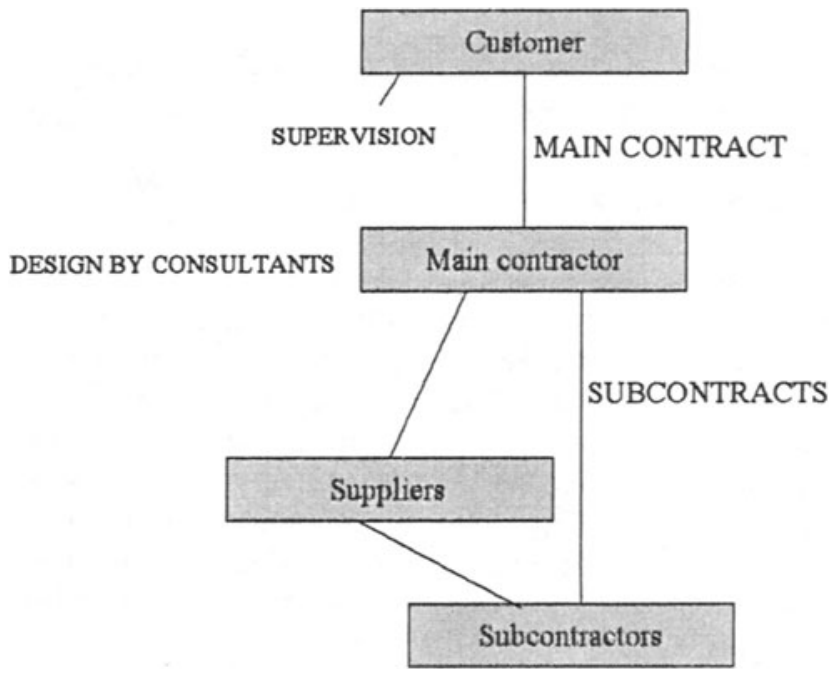

Figure 2 - Structure of a turnkey contract 


\subsection{Contract Management}

Contract management is critical to the success of business. It is important to understand the dynamic role of contract management in a multifunctional team environment and to examine the various aspects of authority versus responsibility. Contracts are legal mechanisms that are used to manage the risks and changes inherent in conducting business.

A typical power plant delivery project consists of various contracts. There are consulting contracts, contracts for delivery of machinery, materials etc., for installation, for supervision, for erection, just to name a few. In case some project participants form a consortium they will sign a consortium agreement, which defines the relationship between the members of a consortium. For more information about consortium and particularly about consortium as a virtual enterprise see (Laurikkala et al, 1999).

In a general type of a contact (e.g. a contract for delivery) a main contractor drafts a contract with a customer, defining technical and general matters specific to the delivery. Other essential matters are e.g.:

- definitions

- type and scope of delivery

- erection site

- time schedule

- price of delivery

- changes, additions, extra work

- terms of payment

- security issues

- liability and passing of risk or loss or damage

- insurance

- clauses on test run and acceptance of the plant

- clauses on inspection of the plant

- liquidated damages

- effectiveness of contract

- appendices.

Integral parts of the contracts are appendices the amount of which may go up to 30. They may include general contract conditions, technical data and guarantee, technical specification, project time schedule, insurance, invoicing instructions, financial guarantees, shipping instructions and reporting methods.

General conditions of contract is usually a standard or a semi-standard document which defines relations between the parties, secondarily with technical matters. Matters defined may be e.g. obligations of the supplier and the purchaser, work environmental responsibility, effects of changed legislation, changes, force majeure, clauses on test run, taking-over, inspection and acceptance. They may also include liabilities, patent rights, termination and disputes.

It is very important to define the ranking of the documents in case of contradictory legal stipulations and technical information. Normally the main contract supersedes appendices, last document supersedes older ones and technical explanations and specifications supersede drawings. 


\section{SIMO-3: DESCRIPTION}

In order to improve their networked co-operation and supply chain management four Finnish power plant contractors started a project the aim of which was to develop a strategic information system for virtual supplies. Simo-3 is a result of the project: a web based software tool for planning, management and control of the virtual supply chain of large distributed projects in a multi-project environment. It consists of a resource, product and business modelling part, a project modelling part and a simulator in Simo-3 and of separate and analysis tools in MS Excel and MS Project. Simo is developed in a project started in 1996 at Tampere University of Technology with a close co-operation of four industrial case companies from the field of power plants.

Simo is particularly designed for the preliminary planning phase, i.e. for contracting, defining project scope and selecting suppliers. It is also a powerful tool for a project manager in company-wise resource, product and business modelling, selection of partners, scheduling, resource and logistics management, analysis of results and project follow-up.

There are also advantages of a strategic nature. The use of the tool supports the networking development and the co-operation of the companies. Contract management and risk and profit sharing get easier when supported by a permanent network and a common contract format. The tool can also help in finding new, alternative ways to operate and in demonstrating the project progress for customers.

Simo-3 has been in a company-wise test use of the case companies since the beginning of the year 2000. The distributed use is to begin when the companies are familiar with the tool and when they have modelled their own resource, business and product models.

\section{CONTRACT MANAGEMENT IN SIMO-3}

\subsection{Contracting}

In a current business environment it cannot be assumed that everybody involved in contract management works in the same office, on the same internal network. Therefore, the old, centralized way of managing contracts is a flawed model. A system that can be accessed by anyone with an Internet connection gives maximum flexibility (Vincent, 2000).

There are certain requirements for a good electronic contract management system. It should be easily accessed and intuitive. To support the networking development of the companies, it should also be distributed and Web enabled. The system should be designed with open architecture for end-to-end integration. Handling of complex contracts should be supported. The system should be flexible but rule based, accessible and secure (Vincent, 2000).

In the development of Simo, the aforementioned requirements have been respected. The use of Simo starts by modeling the common product model describing the product to be delivered to the customer (e.g. power plant, pulp or 
paper mill). The work continues by modeling the resource and business models of each company. When the models are ready, the distributed use of Simo can begin.

The users start by describing the project (effective and end dates, site location, partners, specific parameters of the simulation run etc.) in a project outline window. This makes it easier to study and compare projects and different simulation runs of the same project later.

The most important contract information (contract description, contract name, customer, supplier, price and deliveries) is entered to Simo-3 by using a contract tool (Figure 3). One can also go through a detailed contract form, made in cooperation by the lawyers of the seven case companies. This commonly accepted contract form is to simplify the usually complicated contract management. It provides the users with a clear structure of a project contract. The information required includes e.g. scope of supply and delivery limits, terms of delivery, delivery time, contract price, taxes, terms of payment and invoicing, guarantees for advance payment, contact period and guarantee period, tests, certifications and guarantees, force majeure, liquidated damages for delay in delivery and performance guarantees, insurance, cancellation and termination, governing law and settlement of disputes.

In order to make the contract management more effective there are links available for all the terms used in the contract. The links lead to the juridical guidebook of power plant projects. The purpose of the juridical guidebook is to explain and point out certain contractual issues in a power plant project before negotiating and drafting an agreement. The guidebook also includes a dictionary of the terms used in a contract. Both the contract form and the juridical guidebook are available in an electronic format for all the case companies.

\subsection{Supplier Selection}

Selecting and controlling suppliers is a critical success factor for project-oriented companies. In a construction project, about 50 to 60 percent of the costs comes from materials and equipment. (Damodara, 2000) In the field of power plants, the percent can go up to 80. Simo includes a supplier database that contains the following information: supplier name, location, price of the product, delivery time and additional information, for example supplier reliability and performance. This information is modelled to company-wise resource and business models and it forms a static base for project modeling.

Suppliers are selected in a project-modelling phase. This can be done cooperatively by project participants or within a company. The user selects a supplier for a product or a part from the supplier database and then defines terms of delivery, scope and the schedule. It is possible to try out different scopes or alternative suppliers from different locations. This is useful especially in large complex projects: they can be simulated with many different options before the project is started. After Simo has been used for managing real projects it also includes a database of supplier performance in former projects. (Laurikkala and Tanskanen, 2001) 


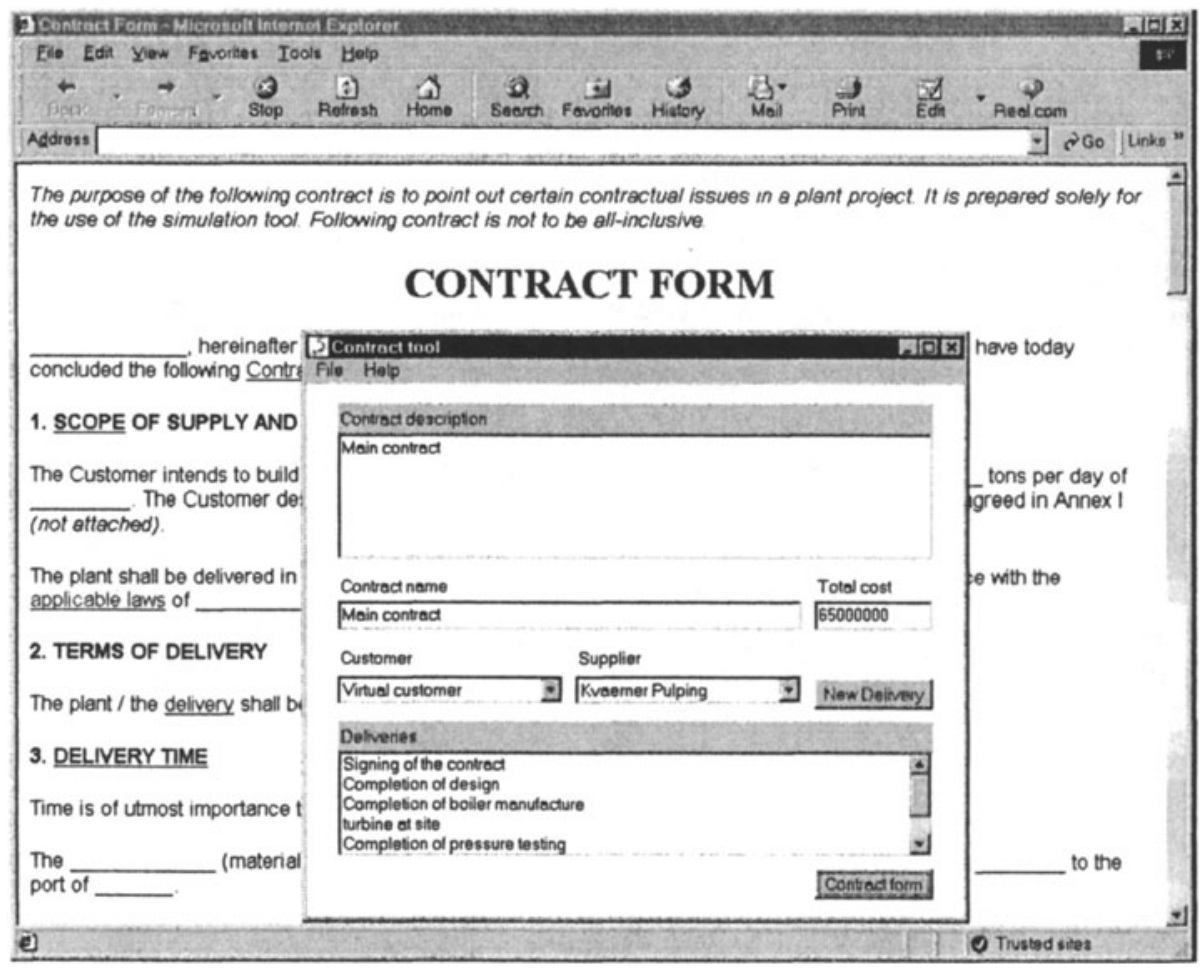

Figure 3 - Contracting tool in Simo-3

When the basic information for the contract is entered and contact is divided into deliveries, the user defines deliveries in a more detailed way. This means selecting the delivery price, terms of delivery, terms of payment and a detailed scope for each delivery. After this the user starts the scheduling phase.

\subsection{Risk Management}

Flaws, mistakes and misunderstandings cause many risks the companies have to face in a contracting phase. So, the best way to prevent risks is to concentrate on proper contract management. The commonly used contract form is a good start and supported with the distributed contracting tool, the companies can easily share and work together for decreasing their risks. Still, there will be unexpected events happening during the projects.

The most important reasons for unexpected events in the field of power plant contractors are changes of various kind (e.g. customer changes), mistakes and misjudgements, rework, inaccurate schedules, quality problems, insufficient information flow, delays, organisational problems (resource sharing etc.) and increase in costs. The companies have to be able to react quickly to these events. So, in a scheduling phase of Simo-3, it is possible to add unexpected events and their consequences to the schedule. Then, the project can be simulated and the results transferred to the separate results and analysis tools in MS Excel and MS Project. 


\section{CONCLUSIONS}

Contract management is an issue of growing interest in the field of project-oriented companies. This is due to the rapidly changing business environment and the fast development of information technology. One has to adapt new ways and new systems to manage contracts: an effective information system is needed. A good electronic contract management system should be easily accessed and intuitive and support the networking development of the companies. It should also be distributed, web enabled and designed with open architecture for end-to-end integration. Flexibility, accessibility and security are musts as well as the ability of handling complex contracts.

Simo-3 is a tool to meet the requirements. It is meant for distributed project management, for modeling and simulating large, complex, one-of-a-kind projects. Simo supports contract management by providing the user with clear contract and delivery tools and with the access to the detailed contract form, the juridical guidebook and the juridical dictionary of power plant projects. Simo also supports the supplier selection by providing the supplier database of available suppliers and of their performance in former projects.

\section{REFERENCES}

1. Baccarani $D$, Archer $R$ The risk ranking of projects: a methodology. International Journal of Project Management. 19, 2000: 139-145.

2. Chandrashekar A, Schary PB Toward the Virtual Supply Chain: The Convergence of IT and Organization. The International Journal of Logistics Management. Vol. 10, Number 2. 1999: 27-39.

3. Cullen PA. Contracting, co-operative relations and extended enterprises. Technovation, 20, 2000: 363372.

4. Damodara U Global Project Management - Not Business As Usual, Journal of Management in Engineering, November/December 2000: 29-33.

5. Evaristo R, Fenema PC A typology of project management: emergence and evolution of new forms. International Journal of Project Management. Vol. 17, No. 5, 1999: 275-281.

6. Gaythorpe RS Satisfactory project completion. Engineering Management Journal. June 1999: 145-151

7. Laurikkala H, Tanskanen K Support System for Virtual Supplier Selection of Networked, ProjectOriented Companies in the Proc. of the 6th International Symposium on Logistics, 8-11 July 2001: 293-300.

8. Laurikkala H, Tanskanen K, Nevalainen P, Vainio-Mattila M Consortium as a Virtual Enterprise in Project Planning in the Proc. of the 5th International Conference on Concurrent Enterprising, 15-17 March 1999: 3-10.

9. Martin A A simulation engine for custom project management education. International Journal of Project Management, 18, 2000: 201-213.

10. Pender $\mathrm{S}$ Managing imcomplete knowledge: Why risk management is not sufficient? International Journal of Project Management, 19, 2000: 79-87.

11. Raz T, Michael E Use and benefits of tools for risk management. International Journal of Project Management, 19, 2001: 9-17.

12. Tan Y-H., Thoen W INCAS: a legal expert system for contract terms in electronic commerce. Decision Support System. 29, 2000: 389-411.

13. Vincent $L$ The Electronic Revolution in Contract Management, Contract Management, November, 2000. 